\title{
Practical Learning Media in Subject Maintenance of Chassis and Power (MCP) Based Online: Simple Learning Using Videos on YouTube
}

\author{
https://doi.org/10.3991/ijim.v15i03.14943 \\ Rabiman Rabiman $\left({ }^{凶}\right)$ \\ Yogyakarta State University, Yogyakarta, Indonesia, \\ Universitas Sarjanawiyata Tamansiswa, Yogyakarta, Indonesia \\ rabimandustjogja.ac.id \\ Putu Sudira, Herminarto Sofyan \\ Yogyakarta State University, Yogyakarta, Indonesia \\ Muhammad Nurtanto \\ Universitas Sultan Ageng Tirtayasa, Banten, Indonesia
}

\begin{abstract}
Practical learning worldwide, especially in vocational education, faces tensions in the achievement of low psychomotor competency outcomes. Various studies have been conducted, such as the engineering of props, simulation tools, animation media, and even real media. However, vocational students need media that are effective, practical, and easy to reinforce concepts, such as YouTube's integrated video media. This study aims to develop practical learning media and measure students' perspectives on maintaining chassis and power (MCP) competencies based on YouTube integrated online videos. The researchers involved material experts, media experts, and practitioner experts in improving the quality of MCP media and 163 respondents as a test of users' perceptions. MCP quality is determined based on the eligibility value on the feasibility of content, language suitability, video output, ease of use, consistency, format, and graphics. The results confirm that all aspects of feasibility, language suitability, ease of use, and graphics on the MCP media are recommended according to YouTube usage. Thus, this study concludes that the online media "YouTube" is effective as a learning method and relevant to users' needs. The involvement of experts is important in the decision to accept and match the quality of the media. The feasibility of the MPC video media uploaded on YouTube is $78.15 \%$ reviewed. Learning-based video on YouTube makes it easy for learners in conceptual understanding of factual understanding.
\end{abstract}

Keywords - Practical media, maintenance of chassis and power (MCP), mobile learning, abstraction skills, complex skills 


\section{Introduction}

The success of vocational education is oriented towards achieving cognitive, psychomotor, and affective competencies. Psychomotor competence is a characteristic that must be technically mastered. On the other hand, psychomotor skills have been used to improve understanding and ability in upgrading skills. Several ways have been done, namely developing various applications-based media, and simplified real approaches. However, learning competencies need to be adjusted. The essence of vocational education is to work [1] in the field and develop a career. Vocational education equips students to master certain and specific competencies and skills [2]. Besides, vocational education teaches abstract and conceptual to contextual (technical) and methodological in constructing competency achievement.

The competencies of maintenance of chassis and power (MCP) in vocational education in the automotive sector consist of several complex components and competencies. The MCP system consists of several units, namely the clutch, propeller shaft, differential, axle, brake, wheels, and tires. The focus of maintenance work in this study is the brake system. The literature on brake systems has been developed, namely modules, emodules, animation, and even real media. However, students still experience difficulties because MCP competencies are very complex. As a result, students cannot fully master it, psychology in practice begins to decline, and motivation becomes low.

The researchers observe that the difficulty level of mastering MCP competencies is a position that lies in complicated components and performance that cannot be observed with the eye open and complex work to be done appropriately. The complex work on MCP competencies based on the Indonesia National Quality Framework, Professional Certification Institute (LSP) Automotive, and Industrial Vocational Training Development Centre (BBLKI) references are as follows: (1) Carrying out component maintenance; (2) Maintaining the brake system; (3) Reading and understanding Engineering drawings; (4) Using and maintaining measuring instruments; (5) Following occupational safety and health procedures (6) Using and maintaining workplace equipment and equipment; (7) Carrying out manual handling operations; (8) Improving the brake system; (9) Overhauling brake system components; (10) Removing, installing and adjusting wheels; (11) Assembling and installing the brake system and its components; and (12) Making minor repairs to the electrical circuit (http://lsptop.co.id/klaster/ pemeliharaan-sistem-rem/).

The number of competency units in brake system work, theoretical learning in class, individual understanding through books, modules, e-modules, and animation is not enough. Some researchers argue that complex competencies require a complete and correct understanding [3]-[5]. Therefore, the weakness of understanding can be completed, and operational practice can be achieved. The advantage obtained is to minimize the occurrence of component damage. Thus, it is necessary to have learning media with practical concepts directly by the workshops' conditions and facilitate access. However, it does not leave the conceptual understanding of theory to improve cognitive abilities. The researchers' conceptual combines existing animation concepts and has an innovative and interactive nature, as evidenced by the actual practice, packaged through interactive videos, and accessed in the online media "YouTube." 
Two important considerations in online access are the simplicity and culture of cooperative students using mobile devices. It is reinforced by previous researchers stating that learning by adopting and using tablets is more flexible [6], [7], for all users without restrictions [8]. This facilitates the learning method, where pre-practice learning can be done at any time. Even during practice, it can be played back as a solution to the negligence factor. Researchers assume that this solution is effective in the MCP practical learning process.

\section{$2 \quad$ Literature Review}

\subsection{Effective learning media}

Learning in the 21st century leads to learning and innovation skills, life and career skills, media, information, and technology skills [9] [10]. One of the efforts to achieve the target is the opportunity for students to learn relevant to the world of work. Therefore, schools need support from the world of work. In the context of technology that applies to a speedy learning process, it is difficult to follow. Furthermore, the carrying capacity of practical learning is limited to a large study group ratio. On the other hand, low understanding causes a high risk of failure and frequent damage to practical equipment. Thus, practical learning strategies must be adapted to technological developments.

A new strategy is needed in the practical learning of the automotive sector before practicing directly. Learning media is a tool to facilitate communication in learning to provide real experiences to learners and improve learning outcomes. Learning should be able to be done at any time and in every place. To facilitate learning that does not recognize space and time, online learning can be used. Online learning provides opportunities for students to interact either directly or indirectly with learning resources and teachers [9]. Besides, e-learning-based learning media can generate new ideas, encourage students to think, act, and focus on all teaching and learning activities [8].

The effectiveness of e-learning is influenced by eleven external factors such as the quality of website content, the quality of technical issues of the website, the quality of website design, usability, website access speed, e-learning system functions, the reliability of e-learning system, facility conditions, top management support, student awareness, and academic staff awareness about the use of e-learning systems. Digital-based e-learning has many benefits and can support broad-scale learning, and can be applied in formal and non-formal learning [13].

\subsection{YouTube as online learning media}

Video can be used as a medium of learning in cognitive, affective, and psychomotor aspects [14] [15]. As an interaction tool, video can create a strong understanding because it touches several senses simultaneously and can be integrated with the internet (online). They are especially attractive to visual learners who learn best by watching attractive format short videos rather than simply reading or listening to subject matter 
[16]. Online video can be integrated with social media built based on 7C (content, community, conversation, capital (social), culture, collaboration, and conversion, respectively). One of the popular social media for sharing videos is YouTube. It is a free site for storing and distributing videos. As a learning medium, YouTube gives educators the freedom to direct learners to see videos already available or upload their own videos [17].

In choosing an online learning video, it is necessary to consider factors related to the content, quality, material, distribution channels, gamification, social media, format, and language [16]. A YouTube integrated video that is already popular and easily accessible cannot be avoided as a complementary tool in education, but the use of YouTube's video library should be peer-reviewed [18]. This is because the overall quality of YouTube videos is generally low, particularly mechanical engineering education videos. Therefore, educational professionals and organizations should be encouraged to provide more useful material and animated videos to people who are looking for reliable information on the internet [19]-[21]. Videos directly connected to coursework usually have higher interest, so students watch the same video several times while working on assignments [16].

\subsection{Mobile application: Learning methods and easy access}

The term mobile learning (M-Learning) refers to mobile devices and handheld devices such as smartphones, laptops, and tablet PCs in teaching and learning delivery [11]. Mobile learning is believed to improve the teaching and learning process. An Android-based learning program application [6] can be used for learning engineering effectively [23]. Mobile devices as learning media play an important role in life. Their portability and ease of use have made them an integral part of our daily activities, as they are continuously connected to the internet, providing multiple applications simultaneously [24].

YouTube integrated videos as M-Learning can be played easily on almost all mobile devices with a free application [17]. The use of applications is influenced by several factors, namely efficiency, effectiveness, satisfaction, errors, accessibility, and understanding. The quality of media in M-Learning needs to be evaluated for content, pedagogical, and Video output aspects. The use of mobile applications by educators must also pay attention to grammar and attractive Video output [25]. [26], Meanwhile, from the student side, evaluation of M-Learning includes evaluating user satisfaction, learning effectiveness, behavior change, and impact.

\section{$2.4 \quad$ Research questions}

Developing practical learning media for MCP is to understand content knowledge conceptualized with methods and ease of access using Android that is suitable for student needs. The position of online-based MCP practice learning media as a supporting capacity, strengthening students' content knowledge in facilitating the concept of practical implementation and can be played back when students have difficulty doing MCP 
caring. With media, learning practices can equate understanding the multi-representation of students. Therefore, the research questions are formulated as follows:

a. What is the concept of developing practical learning media on online-based MCP that is valid and meets instructional media rules in higher education?

b. What is the media's level of feasibility in answering the needs of students who facilitate content knowledge before practice is applied?

\section{$3 \quad$ Research Methodology}

This development research is conducted using the Four-D development model approach by Semmel \& Semmel (1974). The 4-D model is widely applied to interactive multimedia, teaching aids and work, worksheets, and construction projects [27]. This development model consists of four phases: the definition phase, the design phase, the development phase, and the dissemination phase. At the end of each development stage, an evaluation (E1, E2, E3, and E4) is carried out to maintain all aspects of media development. Media development is processed through 4 stages, resulting in a valid and feasible product by testing. The concept of learning media is good in answering users' needs; then, the MCP media are tested in limited tests and field tests. The stages of the 4-D development, conceptual model are as follows:

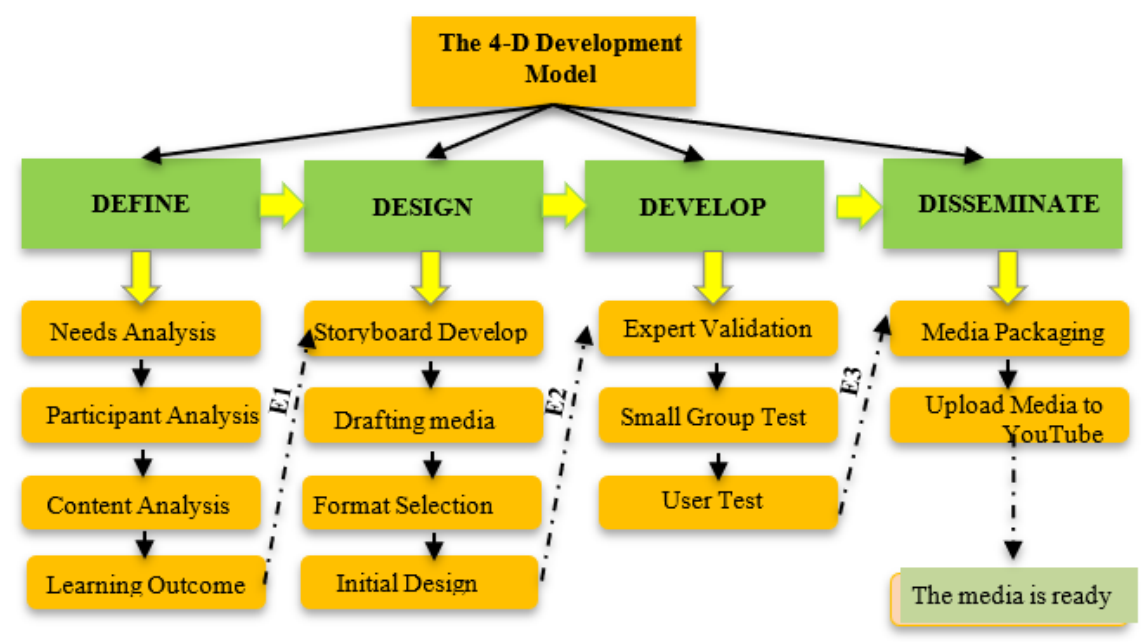

Fig. 1. Development model of 4D based "YouTube" online learning

The procedure for developing MCP practice learning media with the 4-D model is as follows:

a) The define phase is a key stage in the development process with a priority scale, answering the competence of the world of work in the concept of learning. At this 
stage, the researchers' analytical skills are needed from various considerations, namely the need for competency in the world of work, Indonesia National Quality Framework standards, and curriculum. Other considerations, students' characteristics, habits, and availability of MCP practicum equipment. This stage produces analytical content that suits students' needs conceptually and becomes the learning objective.

b) The design phase is the design stage of MCP practice learning media based on the initial stage identification. The researchers created a media storyline, an outline of the media content, the selection of support formats such as adobe premiere pro CC, CorelDraw X7, and Adobe audition CC supporting media, which were combined, and the initial product creation.

c) The development Phase is an advanced stage of the initial product being declared complete and validated by supervisors or experts in their fields or expert practitioners. The input of validation results is used to improve the MCP media. If the evaluation has been made improvements, the researchers conduct an alpha test in a limited group to see that the MCP media is running well. The final stage of this phase is the beta test for users comprising of 163 students.

d) The Disseminated phase is the final packaging and checking stage, and the MCP media is uploaded to the YouTube space. At this stage, the MCP practice learning media are ready to be used in the learning process.

Online-based MCP practice learning media experiences different stages when compared to the development of other models. The difference in stages is that the video upload process in the YouTube space is carried out in the disseminated phase. Several development models are carried out in the development phase. The researchers analyze the MCP media in an appropriate state before the upload process and meet the criteria. Another reason is to avoid the public's perceptions that YouTube can be accessed widely so that that information can be accounted for. Evaluation and monitoring and researchers do at the end of each stage of each development phase.

\section{Design and Development of Learning Media}

Educational media are a fundamental tool in the learning process [28]. The existence of the media determines the success of learning from abstraction or conceptual to contextual. However, the conceptual framework for media design and development is supported by various studies and synthesized in this media assessment. Media assessment indicators were synthesized from Papadakis [7], [29], Triyono [30], Scott [31], and Mehdi [32]. Aspects of assessment of the synthesis results following the MCP's needs are the feasibility of content, language suitability, video output, ease of use, consistency, format, and graphics. The conceptual framework for testing MCP learning media is as follows: 


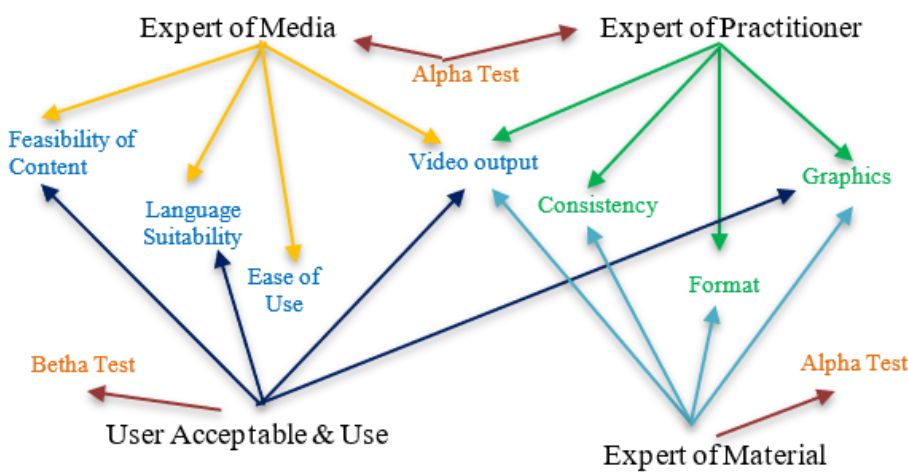

Fig. 2. Design and development framework MCP based on expert media, experts of practitioners, and users' perception indicators

Each aspect of the media is developed in the instrument and tested by each expert simultaneously and according to the expert's acceptance of the aspect. Besides, the study's MCP media were divided into two test stages, namely the alpha test and beta test. Experts carry out the alpha test before the media is judged worthy of user testing. Users carry out the beta test on a small and limited scale.

Respondents in this study involved 184 respondents with the following representative data.

Table 1. Respondents' data in the validation of MCP media feasibility

\begin{tabular}{|l|c|c|}
\hline \multicolumn{1}{|c|}{ Characteristics } & Number (n) & Percentage (\%) \\
\hline Expert Validation Respondents & & \\
\hline Expert of material & 8 & 4.26 \\
\hline Expert of media & 8 & 4.26 \\
\hline Expert of Practitioner & 9 & 4.79 \\
\hline User/Student & 163 & 8.70 \\
\hline Age (years) & & 63.19 \\
\hline $18-20$ & 103 & 36.81 \\
\hline $21-24$ & 60 & 34.36 \\
\hline Study levels & & 20.25 \\
\hline Two semesters & 56 & 45.40 \\
\hline Four semesters & 33 & \\
\hline Six semesters & 74 & 5.52 \\
\hline Education Background & & 94.48 \\
\hline Senior High School & 9 & \\
\hline Vocational School & 154 & \\
\hline
\end{tabular}

Type of data, this development research includes the validation of media and material experts and practitioners in assessing MCP media criteria (according to Fig. 1). Then the product is evaluated. User feasibility testing is carried out in limited class trials 
and extensive user trials (Table 1). The decision results recommend that the media have met and used for the MCP competency learning process.

The instrument of data collection, using a question item questionnaire with assessment indicators according to Fig. 2. The rating scale uses level 4 with positive or neutral questions, where the rating scale 1 shows the lowest level, and the rating scale 4 shows the highest level. One variable consists of several indicators, which are added together in one variable as MCP media decision making. Instrument indicators were developed from a synthesis of previous media researchers. Data were collected by survey using the google form platform. The data's validity and reliability are generated from expert test results with the growth of decision acceptance. Under the decision area, it is stated that the media need to be evaluated or declared unfit for use.

The technique of data analysis, determining MCP media decisions at the stage of expert validation and user testing into five categories, namely $\mathrm{C} 1$ "very less valid or very less feasible; C2 "less valid or less feasible"; C3 "fairly valid or fairly feasible; C4 "valid or feasible, and C5 "very valid or very feasible." The number of respondents determines decision making, the rating scale was chosen, and question items for each fixed variable. The following is a summary table for determining the category of MCP media. The success of MCP media can be used properly if it meets the valid or feasible, and very valid or very feasible categories. Data were analyzed using descriptive qualitative methods with the following formulations:

$$
{ }^{\mathrm{a}} \mathrm{C} \leq \mathrm{Mi}-1.5 \text { Sbi }
$$

$$
\begin{gathered}
{ }^{\mathrm{b}} \mathrm{Mi}-1.5 \mathrm{Sbi}<\mathrm{C} \leq \mathrm{Mi}+(-0.5) \mathrm{Sbi} \\
{ }^{\mathrm{c}} \mathrm{Mi}-0.5 \mathrm{Sbi}<\mathrm{C} \leq \mathrm{Mi}+0.5 \mathrm{Sbi} \\
{ }^{\mathrm{d}} \mathrm{Mi}+0.5 \mathrm{Sbi}<\mathrm{C} \leq \mathrm{Mi}+1.5 \mathrm{Sbi}
\end{gathered}
$$

${ }^{\mathrm{e}} \mathrm{C}>\mathrm{Mi}+1.5 \mathrm{Sbi}$

\begin{tabular}{|c|c|c|c|c|c|c|c|}
\hline \multirow{2}{*}{ No } & \multirow{2}{*}{ Aspect } & \multirow{2}{*}{ Item } & \multicolumn{5}{|c|}{ Category Score limit } \\
\hline & & & $V L V / V L F^{a}$ & $L V / L F^{b}$ & $F V / F F^{c}$ & $V / F^{d}$ & $V V / V F^{e}$ \\
\hline & \multicolumn{7}{|c|}{ Experts of Media (8 respondents) } \\
\hline 1 & $\begin{array}{l}\text { Feasibility of } \\
\text { content }\end{array}$ & 8 & $\leq 111$ & $112-143$ & $144-175$ & $176-207$ & $>208$ \\
\hline 2 & $\begin{array}{l}\text { Language suita- } \\
\text { bility }\end{array}$ & 4 & $\leq 55$ & $56-71$ & $72-87$ & $88-103$ & $>104$ \\
\hline 3 & Video output & 5 & $\leq 69$ & $70-89$ & $90-109$ & $110-229$ & $>130$ \\
\hline \multirow[t]{2}{*}{4} & Ease of use & 3 & $\leq 41$ & $42-53$ & $54-65$ & $66-77$ & $>78$ \\
\hline & \multicolumn{7}{|c|}{ Expert of Material (8 respondents) } \\
\hline 5 & Video output & 5 & $\leq 69$ & $70-89$ & $90-109$ & $110-229$ & $>130$ \\
\hline 6 & Consistency & 3 & $\leq 41$ & $42-53$ & $54-65$ & $66-77$ & $>78$ \\
\hline 7 & Format & 3 & $\leq 41$ & $42-53$ & $54-65$ & $66-77$ & $>78$ \\
\hline 8 & Graphics & 5 & $\leq 69$ & $70-89$ & $90-109$ & $110-229$ & $>130$ \\
\hline
\end{tabular}

${ }^{\mathrm{d}-\mathrm{e}}$ media decisions can be accepted and used.

Table 2. Limits for determining categories of MCP media 
Paper-Practical Learning Media in Subject Maintenance of Chassis and Power (MCP) Based Online...

\begin{tabular}{|c|c|c|c|c|c|c|c|}
\hline \multirow{2}{*}{ No } & \multirow{2}{*}{ Aspect } & \multirow{2}{*}{ Item } & \multicolumn{5}{|c|}{ Category Score limit } \\
\hline & & & $V L V / V L F^{a}$ & $L V / L F^{b}$ & $F V / F F^{c}$ & $V / F^{d}$ & $V V / V F^{e}$ \\
\hline & \multicolumn{7}{|c|}{ Expert of Practitioner $(9$ respondents } \\
\hline 9 & Video output & 8 & $\leq 125$ & $126-161$ & $162-197$ & $198-233$ & $>234$ \\
\hline 10 & Consistency & 4 & $\leq 62$ & $63-80$ & $81-98$ & $99-116$ & $>117$ \\
\hline 11 & Format & 5 & $\leq 77$ & $78-100$ & $101-122$ & $123-145$ & $>146$ \\
\hline \multirow[t]{2}{*}{12} & Graphics & 3 & $\leq 46$ & $47-59$ & $60-73$ & $74-86$ & $>87$ \\
\hline & \multicolumn{7}{|c|}{ Users (163 respondents) } \\
\hline 13 & $\begin{array}{l}\text { Feasibility of } \\
\text { content }\end{array}$ & 9 & $\leq 2.566$ & 2.567-3.299 & $3.300-4.033$ & 4.034-4.766 & $>4.767$ \\
\hline 14 & $\begin{array}{l}\text { Language suita- } \\
\text { bility }\end{array}$ & 4 & $\leq 1.140$ & $1.141-1.466$ & $1.467-1.792$ & $1.793-2.118$ & $>2.119$ \\
\hline 15 & Video output & 6 & $\leq 1.710$ & 1.711-2.199 & $2.200-2.688$ & $2.689-3.177$ & $>3.178$ \\
\hline 16 & Graphics & 6 & $\leq 1.710$ & 1.711-2.199 & $2.200-2.688$ & $2.689-3.177$ & $>3.178$ \\
\hline
\end{tabular}

\section{$5 \quad$ Result}

\subsection{Development description}

The development product is MPC media based on online learning following the 4D model. Expert validation is carried out to assess the suitability of online media before use. Material experts consisting of lecturers from various universities with academic promotion credibility, including Expert Assistants, Lectors, and Head Lecturers in automotive vocational education, indicate that the media in terms of material content has met the requirements of educational media for online learning. Media experts from senior university lecturers contribute to the media's integrity to meet innovative and creative educational media requirements and following work competency innovations. Practitioner experts consisting of vocational high school teachers and automotive industry experts provide recommendations for the suitability of the competencies shown to meet the world of work's competencies. Input from various experts was made improvements to researchers to increase educational media's role, namely MCP in the feasibility of online "YouTube."

The focus of development consists of three brake system competencies (Fig. 3), namely (1) maintaining disc brakes, (2) maintaining drum brakes, and (3) blading the brake system. The concept of a learning media methodology approach with animationbased explanations is working illustrations that cannot be explained directly and practically on direct components. Researchers assess that learning with actual concepts or media following practice will facilitate understanding of initial knowledge [5]. Besides, students during their practice can stop the media or roll back the practical learning process. This condition can prevent serious damage and student psychology in preparation for better practice. 


\subsection{Validation and responses to material experts, media experts, and practitioners}

The following are the results of the evaluation of material expert validation (Table 3), media expert (Table 4), and expert practitioner (Table 5). The assessment criteria refer to Figure 2 according to the capacity and contribution of the expert. Decisions are determined based on the number of scores obtained and included in the category determination (Table 2). Standard deviation (SD) and Standard Error of Mean (SEM) indicate the level of data capability and the distribution of data obtained from expert validation results.

Table 3. Statistical data of media expert validation on MCP media

\begin{tabular}{|c|c|c|c|c|c|c|c|c|}
\hline \multirow{2}{*}{ Aspect } & \multicolumn{4}{|c|}{ Scores } & \multirow{2}{*}{$\begin{array}{l}\text { Total } \\
\text { Score }\end{array}$} & \multirow{2}{*}{ SD } & \multirow{2}{*}{ SEM } & \multirow{2}{*}{ Category } \\
\hline & $R S 4$ & $R S 3$ & RS2 & $R S 1$ & & & & \\
\hline $\begin{array}{l}\text { Feasibility of } \\
\text { content }\end{array}$ & 80.00 & 123.00 & 6.00 & 0.00 & 209.00 & 51.59 & 32.65 & VV \\
\hline $\begin{array}{l}\text { Language suita- } \\
\text { bility }\end{array}$ & 52.00 & 48.00 & 6.00 & 0.00 & 106.00 & 23.64 & 13.34 & VV \\
\hline Video output & 40.00 & 81.00 & 6.00 & 0.00 & 127.00 & 32.27 & 20.93 & $\mathrm{~V}$ \\
\hline Ease of use & 40.00 & 39.00 & 2.00 & 0.00 & 81.00 & 19.27 & 11.22 & $\mathrm{VV}^{*}$ \\
\hline
\end{tabular}

Table 4. Statistical data of material expert validation on MCP media

\begin{tabular}{|c|c|c|c|c|c|c|c|c|}
\hline \multirow{2}{*}{ Aspect } & \multicolumn{4}{|c|}{ Scores } & \multirow{2}{*}{$\begin{array}{l}\text { Total } \\
\text { Score }\end{array}$} & \multirow{2}{*}{ SD } & \multirow{2}{*}{ SEM } & \multirow{2}{*}{ Category } \\
\hline & $R S 4$ & $R S 3$ & $R S 2$ & RS1 & & & & \\
\hline Video output & 56.00 & 72.00 & 0.00 & 1.00 & 129.00 & 32.25 & 16.13 & $\mathrm{~V}$ \\
\hline Consistency & 32.00 & 42.00 & 4.00 & 0.00 & 78.00 & 17.91 & 8.95 & SV \\
\hline Format & 16.00 & 45.00 & 10.00 & 0.00 & 71.00 & 16.74 & 8.37 & $\mathrm{~V}$ \\
\hline Graphics & 32.00 & 78.00 & 10.00 & 1.00 & 121.00 & 29.79 & 14.89 & $\mathrm{~V}$ \\
\hline
\end{tabular}

Table 5. Statistical data of practitioner validation on MCP media

\begin{tabular}{|l|c|c|c|c|c|c|c|c|}
\hline \multirow{2}{*}{ Aspect } & \multicolumn{4}{|c|}{ Scores } & \multirow{2}{*}{$\begin{array}{c}\text { Total } \\
\text { Score }\end{array}$} & \multirow{2}{*}{ SD } & \multirow{2}{*}{ SEM } & \multirow{2}{*}{ Category } \\
\cline { 2 - 9 }$n$ & $\boldsymbol{R S 4}$ & $\boldsymbol{R S 3}$ & $\boldsymbol{R S 4}$ & $\boldsymbol{R S 1}$ & & & \\
\hline Video output & 132.00 & 111.00 & 4.00 & 0.00 & 247.00 & 60.23 & 30.11 & $\mathrm{SV}^{*}$ \\
\hline Consistency & 32.00 & 84.00 & 0.00 & 0.00 & 116.00 & 34.34 & 17.17 & $\mathrm{~V}$ \\
\hline Format & 68.00 & 81.00 & 2.00 & 0.00 & 151.00 & 37.04 & 18.52 & $\mathrm{SV}^{*}$ \\
\hline Graphics & 44.00 & 45.00 & 2.00 & 0.00 & 91.00 & 21.76 & 10.88 & $\mathrm{SV}^{*}$ \\
\hline
\end{tabular}

Note:

RS4: Rating scale 4, RS3: Rating scale 3, RS2: Rating scale 2, RS1: Rating scale 1

SD: Standard Deviation

SEM: Standard Error of Mean

The data in Fig. 4 shows the rating scale distribution in percentage according to the expert validation assessment variable. Researchers can conclude that expert practitioners consisting of a teacher and industry players (world of work) provide the highest level online-based MCP media assessment based on each expert's validation chart. This shows that what is packaged by the media has credibility in work and education, namely vocational schools expressed by teachers. The validation of media experts and material 
experts represented by lecturers from various universities has made decisions based on the overall criteria that have been valid or fulfilled. Based on the choice of the rating scale, it is dominated at level 3 and followed by scale level 4, scale level 2, and scale level 1. All aspects of scale assessment function well.

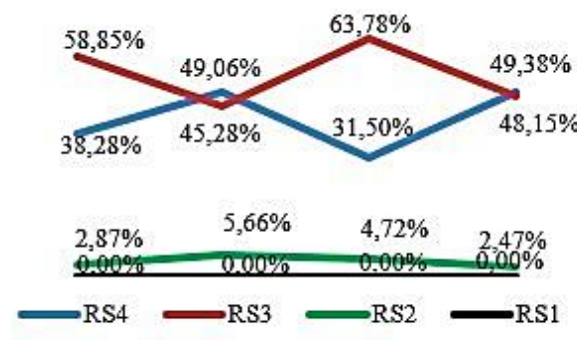

(a)

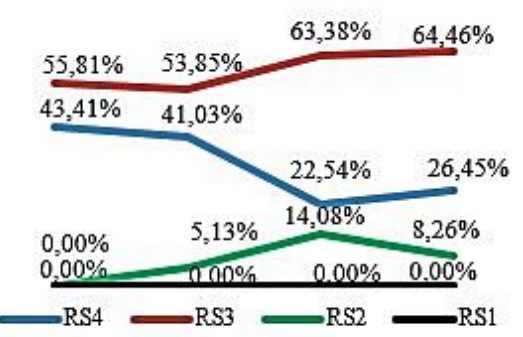

(b)

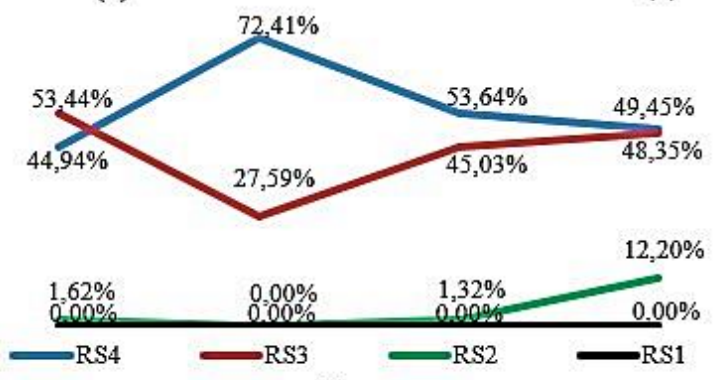

(c)

Fig. 3. Chart (a) material experts, (b) media experts, (c) and practitioners based on the percentage distribution Scala rating

The researchers concluded that the results of expert validation and the relationship between aspects of the assessment until the decision met the requirements were valid and very valid (Table 6). All aspects have met the media validation criteria. Thus, it can be done at the next stage of the test, namely the beta test, to measure online MCP media acceptance to users.

Table 6. The Relationship between decision making among experts to the MCP media

\begin{tabular}{|l|c|c|c|l|}
\hline \multicolumn{1}{|c|}{ Aspect } & Expert of media & Expert of material & Expert of practitioner & \multicolumn{1}{|c|}{ Decision } \\
\hline Feasibility of content & VV & $/$ & VV $^{*}$ & VV (satisfy) \\
\hline Language suitability & $\mathbf{V V}$ & $/$ & $\mathbf{V}$ & V (satisfy) \\
\hline Video output & $\mathbf{V}$ & $/$ & $\mathbf{V V}^{*}$ & VV* (satisfy) \\
\hline Ease of use & $\mathbf{V V}^{*}$ & $/$ & $\mathbf{V V}^{*}$ & VV* (satisfy) \\
\hline Consistency & $/$ & VV & $/$ & VV (satisfy) \\
\hline Format & $/$ & $\mathbf{V}$ & $/$ & V (satisfy) \\
\hline Graphics & $/$ & $\mathbf{V}$ & $/$ & V (satisfy) \\
\hline
\end{tabular}

"High validation rate 


\subsection{Eligibility for acceptance and use of media}

The experts' decision on the MCP media determines the next stage of testing, namely the beta test of YouTube users in practical learning. A total of four variables represent the acceptance and use of appropriate YouTube media, namely presentation, language, utility, and graph. A total of 163 respondents were involved in using MCP media on YouTube. The data were collected and displayed in table 7.

Table 7. User test results

\begin{tabular}{|l|c|c|c|c|c|c|c|c|}
\hline \multirow{2}{*}{ Aspect } & \multicolumn{4}{|c|}{ Scores } & \multirow{2}{*}{ Total Score } & \multirow{2}{*}{ SD } & \multirow{2}{*}{ SEM } & \multirow{2}{*}{ Category } \\
\cline { 2 - 9 } & $\boldsymbol{R S 4}$ & $\boldsymbol{R S 3}$ & $\boldsymbol{R S 2}$ & $\boldsymbol{R S 1}$ & & & & $\mathrm{V}^{*}$ \\
\hline Feasibility of content & 1268.00 & 3222.00 & 144.00 & 4.00 & 4638.00 & 1287.64 & 643.82 & $\mathrm{~V}^{*}$ \\
\hline Language suitability & 536.00 & 1467.00 & 54.00 & 3.00 & 2060.00 & 587.67 & 293.83 & $\mathrm{~V}^{*}$ \\
\hline Video output & 688.00 & 2217.00 & 122.00 & 6.00 & 3033.00 & 880.85 & 440.42 & $\mathrm{~V}^{*}$ \\
\hline Graphics & 664.00 & 2193.00 & 152.00 & 5.00 & 3014.00 & 866.35 & 433.17 & $\mathrm{~V}^{*}$ \\
\hline
\end{tabular}

All aspects represent the acceptance and use of MCP media on YouTube in a category that qualifies at a good level, with an average score of $78.15 \%$. The percentage breakdown for each aspect is as follows: (a) aspect of presentation with a score of 4.638 (79.04\%); aspects of language with a score of 2.060 (78.99\%); aspects of utility with a score of $3.033(77.53 \%)$; and aspects of the graph with a score of $3.014(77.04 \%)$. This analysis shows that students can accept YouTube in learning media in weighing these four aspects. It is important to effectively consider YouTube as a medium for learning practices and contributions to other factors.

\section{Discussion and Conclusion}

The concept of developing learning media is stated to be acceptable or feasible from media experts, material experts, and practitioner experts who are obtained respectively invalid and very valid criteria, meaning that they can be continued in the next phase. The small and limited user test phase recommends that the MCP media be received with a decent and near a very decent rating. Of course, the fulfillment of the criteria as a learning medium has been successful from the expert's point of view, and the user has the same concept of acceptance.

In detail, the researchers in the development of YouTube as an effective tool in improving learning [33], [34]. Aspects of material, language, benefits, and graphics have an important contribution to learning, especially practice. Mohhaweni (2018) states that YouTube media provides benefits in learning [33], practical competence has increased [35]. Even psychologically, students in learning become controlled [36] if YouTube media is well managed. The study findings that MCP media have developed content eligibility, language suitability, utility, display, convenience, consistency, format, and graph. It can be developed from other relevant aspects and adapted to the type of media developed in equivalent research.

The researchers conclude that the media effectively delivers messages if the message can be received correctly. The MCP media that have been developed have met the 
criteria as a vocational education medium. This shows that the development process is appropriate and increases acceptance of understanding. Thus, YouTube can be used as a learning media for practical competence that is clearer and easier to accept.

The MCP media provides comfort and acceptance of students' competency aspects as evidenced by perceptions on the elements of material understanding, language use, benefits, and graphs of MCP media in the feasible category. However, it is necessary to carry out further studies from the psychomotor aspect after using this media. Media developed is not the only medium that is good, but future researchers can develop MCP media innovatively and interactively with AR or VR assistance so that students can feel the real conditions when doing simulations. Any media is defined as a catalyst that constructs knowledge before students are ready to practice. Besides, construction can be carried out at various stages or in the learning process, so the concept of repetitive media and bringing the actual situation is important for future researchers.

\section{$7 \quad$ Acknowledgement}

This work supported by the Institute for Research, Development and Community Service (LP3M) at Universitas Sarjanawiyata Tamansiswa, Yogyakarta, Indonesia, in accordance with the Internal Research Implementation Agreement Letter No: 25/UST/LP3M/ PUSLIT/PTU/K/VII/2020.

\section{$8 \quad$ References}

[1] M. Pavlova, 'Technology and Vocational Education for Sustainable Development - Empowering Individuals for the Future,' 2009. https://www.springer.com/gp/book/9781402052781 (accessed Mar. 28, 2020).

[2] S. Billett, Vocational Education: Purposes, Traditions and Prospects. Springer Nether-lands, 2011.

[3] M. Nurtanto, Z. Arifin, H. Sofyan, W. Warju, and S. Nurhaji, 'Development of Model for Professional Competency Assessment (PCA) in Vocational Education: Study of the Engine Tune-Up Injection System Assessment Scheme', J. Tech. Educ. Train., vol. 12, no. 2, Art. no. 2, Feb. 2020, Accessed: Jun. 30, 2020. [Online]. Available: https://publisher.uthm.edu.my/ojs/index.php/JTET/article/view/5152

[4] Z. Arifin, M. Nurtanto, A. Priatna, N. Kholifah, and M. Fawaid, 'Technology Andragogy Work Content Knowledge Model as a New Framework in Vocational Education: Re-vised Technology Pedagogy Content Knowledge Model', TEM J., vol. 9, no. 2, pp. 786-791, May 2020, https://doi.org/10.18421/tem92-48

[5] S. Suyitno, R. Y. Purwoko, Y. Widiyono, D. Jatmoko, M. Nurtanto, and Z. Hassan, 'Development of Learning Media for Automotive Charging System Based on Macromedia Flash Vocational School', Univers. J. Educ. Res., vol. 8, no. 11C, pp. 64-71, Nov. 2020, https://doi.org/10.13189/ujer.2020.082308

[6] S. Papadakis, M. Kalogiannakis, and N. Zaranis, 'Educational apps from the Android Google Play for Greek preschoolers', Comput. Educ., vol. 116, no. C, pp. 139-160, Jan. 2018, https://doi.org/10.1016/j.compedu.2017.09.007 
[7] S. Papadakis, M. Kalogiannakis, E. Sifaki, and N. Vidakis, 'Evaluating Moodle use via Smart Mobile Phones. A case study in a Greek University', EAI Endorsed Trans. Creat. Technol., vol. 5, no. 16, Jul. 2018, Accessed: Nov. 08, 2020. [Online]. Available: https://eudl.eu/doi/10.4108/eai.10-4-2018.156382. https://doi.org/10.4108/eai.10-4-2018. $\underline{156382}$

[8] M. Kalogiannakis and S. Papadakis, 'Evaluating pre-service kindergarten teachers' intention to adopt and use tablets into teaching practice for natural sciences', p. 15. https://doi. org/10.1504/ijmlo.2019.10016617

[9] T. Anderson and J. Dron, Teaching Crowds: Learning and Social Media. Athabasca University Press, 2014.

[10] N. Kholifah, P. Sudira, R. Rachmadtullah, M. Nurtanto, and S. Suyitno, 'The effective-ness of using blended learning models against vocational education student learning motivation', Int. J. Adv. Trends Comput. Sci. Eng., vol. 9, no. 5, pp. 7964-7968, 2020, https://doi. org/10.30534/ijatcse/2020/151952020

[11] Y. Friesem, 'Teaching Truth, Lies, and Accuracy in the Digital Age: Media Literacy as Project-Based Learning', Journal. Mass Commun. Educ., vol. 74, no. 2, pp. 185-198, Jun. 2019, https://doi.org/10.1177/1077695819829962

[12] S. Sumarwati, H. Fitriyani, F. M. A. Setiaji, M. H. Amiruddin, and S. A. Jalil, 'Developing Mathematics Learning Media Based on E-Learning using Moodle on Geometry Subject to Improve Students' Higher Order Thinking Skills', Int. J. Interact. Mob. Technol. IJIM, vol. 14, no. 04, Art. no. 04, Mar. 2020, Accessed: Nov. 08, 2020. [Online]. Available: https://www.online-journals.org/index.php/i-jim/article/view/12731. https://doi.org/10.39 91/ijim.v14i04.12731

[13] N. W. A. Majid, S. Fuada, M. K. Fajri, M. Nurtanto, and R. Akbar, 'Progress report of cyber society v1.0 development as a learning media for Indonesian society to support EFA', Int. J. Eng. Pedagogy, vol. 10, no. 4, pp. 133-145, 2020, https://doi.org/10.3991/ijep.v10i4.13085

[14] S. R. Lincoln, Mastering Web 2.0: Transform Your Business Using Key Website and Social Media Tools. Kogan Page Publishers, 2009. https://doi.org/10.1108/07363761111116015

[15] D. Ratnawati, W. Mustafa Kusuma, S. Setuju, M. Nurtanto, and W. Widodo, 'Development of Job Sheet Lathe Machining Practice Based on Animation Video as Interactive Learning Media', J. Phys. Conf. Ser., vol. 1573, p. 012005, Jul. 2020, https://doi.org/10.1088/1742$\underline{6596 / 1573 / 1 / 012005}$

[16] S. Korkut, R. Dornberger, P. Diwanji, B. P. Simon, and M. Maerki, 'Success Factors of Online Learning Videos', Int. J. Interact. Mob. Technol. IJIM, vol. 9, no. 4, Art. no. 4, Sep. 2015, Accessed: Nov. 08, 2020. [Online]. Available: https://online-journals.org/index.php/ijim/article/view/4460. https://doi.org/10.3991/ijim.v9i4.4460

[17] J. Bozarth, Social Media for Trainers: Techniques for Enhancing and Extending Learning, 1st edition. San Francisco: Pfeiffer, 2010.

[18] M. Farag, D. Bolton, and N. Lawrentschuk, 'Use of YouTube as a Resource for Surgi-cal Education-Clarity or Confusion', Eur. Urol. Focus, vol. 6, no. 3, pp. 445-449, May 2020, https://doi.org/10.1016/j.euf.2019.09.017

[19] H. Celik, O. Polat, C. Ozcan, S. Camur, B. E. Kilinc, and M. Uzun, 'Assessment of the Quality and Reliability of the Information on Rotator Cuff Repair on YouTube', Orthop. Traumatol. Surg. Res., vol. 106, no. 1, pp. 31-34, Feb. 2020, https://doi.org/10.1016/ j.otsr.2019.10.004

[20] M. F. Ferhatoglu, A. Kartal, U. Ekici, and A. Gurkan, 'Evaluation of the Reliability, Utility, and Quality of the Information in Sleeve Gastrectomy Videos Shared on Open Access Video Sharing Platform YouTube', Obes. Surg., vol. 29, no. 5, pp. 1477-1484, 2019, https://doi.org/10.1007/s11695-019-03738-2 
[21] M. F. Aydin and M. A. Aydin, 'Quality and reliability of information available on YouTube and Google pertaining gastroesophageal reflux disease', Int. J. Med. Inf., vol. 137, p. 104107, May 2020, https://doi.org/10.1016/j.ijmedinf.2020.104107

[22] A. Al-Hunaiyyan, R. Alhajri, and S. Al-Sharhan, 'Instructors Age and Gender Differences in the Acceptance of Mobile Learning', Int. J. Interact. Mob. Technol. IJIM, vol. 11, no. 4, Art. no. 4, May 2017, Accessed: Nov. 08, 2020. [Online]. Available: https://online-journals.org/index.php/i-jim/article/view/6185. https://doi.org/10.3991/ijim.v11i4.6185

[23] S. Papadakis and M. Kalogiannakis, 'Mobile educational applications for children: what educators and parents need to know', Int. J. Mob. Learn. Organ., vol. 11, no. 3, pp. 256-277, Jan. 2017, https://doi.org/10.1504/ijmlo.2017.085338

[24] E. Sher-Censor, M. Benish-Weisman, L. Gal, and S. Karni, 'The associations between national identity and adjustment: What can we learn from autobiographical narratives?', Int. J. Intercult. Relat., vol. 67, pp. 12-24, Nov. 2018, https://doi.org/10.1016/j.ijintrel.2018.08. $\underline{003}$

[25] M.-H. Cho and D. A. Castañeda, 'Motivational and affective engagement in learning Spanish with a mobile application', System, vol. 81, pp. 90-99, Apr. 2019, https://doi.org/ 10.1016/j.system.2019.01.008

[26] S. Papadakis, M. Kalogiannakis, and N. Zaranis, 'Designing and creating an education-al app rubric for preschool teachers', Educ. Inf. Technol., 2017, https://doi.org/10.1007/ $\underline{\mathrm{s} 10639-017-9579-0}$

[27] D. G. M. Naik, 'Integrated 4D Model Development for Planning and Scheduling of a Construction Project using Geographical Information System', p. 5.

[28] K.-P. Mehdi, Educational Technology Use and Design for Improved Learning Opportunities. IGI Global, 2014.

[29] S. Papadakis, 'Evaluating pre-service teachers' acceptance of mobile devices with regards to their age and gender: a case study in Greece', Int. J. Mob. Learn. Organ., vol. 12, no. 4, p. 336, 2018, doi: 10.1504/IJMLO.2018.095130. https://doi.org/10.1504/ijmlo.2018.100 $\underline{13372}$

[30] M. B. Triyono, 'The Indicators of Instructional Design for E- learning in Indonesian Vocational High Schools', Procedia - Soc. Behav. Sci., vol. 204, pp. 54-61, Aug. 2015, https://doi.org/10.1016/j.sbspro.2015.08.109

[31] D. M. Scott, The New Rules of Marketing and PR: How to Use Social Media, Online Video, Mobile Applications, Blogs, Newsjacking, and Viral Marketing to Reach Buyers Directly. John Wiley \& Sons, 2017. https://doi.org/10.1002/9781119172499.ch22

[32] K.-P. Mehdi, Encyclopedia of Information Science and Technology, Third Edition. IGI Global, 2014.

[33] S. Moghavvemi, A. Sulaiman, N. I. Jaafar, and N. Kasem, 'Social media as a complementary learning tool for teaching and learning: The case of youtube', Int. J. Manag. Educ., vol. 16, no. 1, pp. 37-42, Mar. 2018, https://doi.org/10.1016/j.ijme.2017.12.001

[34] A. Shoufan, 'Estimating the cognitive value of YouTube's educational videos: A learning analytics approach', Comput. Hum. Behav., vol. 92, pp. 450-458, Mar. 2019, https://doi.org/ 10.1016/j.chb.2018.03.036

[35] S. N. Aldallal, J. M. Yates, and M. Ajrash, 'Use of YouTubeTM as a self-directed learning resource in oral surgery among undergraduate dental students: a cross-sectional descriptive study', Br. J. Oral Maxillofac. Surg., vol. 57, no. 10, pp. 1049-1052, Dec. 2019, https://doi. org/10.1016/j.bjoms.2019.09.010

[36] Y.-L. Chen, C.-L. Chang, and C.-S. Yeh, 'Emotion classification of YouTube videos', Decis. Support Syst., vol. 101, pp. 40-50, Sep. 2017, https://doi.org/10.1016/j.dss.2017.05.014 


\section{Authors}

Rabiman is an assistant professor in Mechanical Engineering Education, Faculty of Teacher Training and Education, Universitas Sarjanawiyata, and is currently studying doctoral programs in the Postgraduate Program of Yogyakarta State University, Yogyakarta, Indonesia. E-mail: rabiman@ustjogja.ac.id, ID Scopus: 57209463823, Orcid number: 0000-0003-3933-7009.

Putu Sudira is a Professor in technical and vocational education, Electronic engineering education Department of Yogyakarta State University, Yogyakarta, Indonesia. $\mathrm{He}$ is interested in research on the philosophy and perspective of TVET, education in the world of work, vocational education philosophy, and learning strategies. Email: putupanji@uny.ac.id, ID Scopus: 57205235911

Herminarto Sofyan is a professor of Automotive Engineering Education of Yogyakarta State University, Yogyakarta, Indonesia. The title of his professor inauguration speech is the Optimization of Competency Based Learning in Automotive Engineering Vocational Education. Email: hermin@uny.ac.id, ID Scopus: 57194626818, Orcid number: 0000-0002-6357-7152

Muhammad Nurtanto is an assistant professor of Universitas Sultan Ageng Tirtayasa, Department of Mechanical Engineering, Banten, Indonesia. A reviewer on several international journals (IJAME, JEGYS, and JTET) and National Journals (Gravity, Vanos, IJAR). E-mail: mnurtanto23@untirta.ac.id, Orcid number: 00000002-6357-7152.

Article submitted 2020-04-17. Resubmitted 2020-11-28. Final acceptance 2020-11-28. Final version published as submitted by the authors. 